\title{
Influenciar para construir las sombras de la realidad. Youtubers e Influencers en la Era Postdigital
}

\section{Influence to build the shadows of reality. Youtubers and Influencers in the Postdigital Age}

Fechas | En edición: 10/11/2020 - Publicación final: 01/01/2021

\section{Eduardo GARCÍA-BLÁZQUEZ}

Universidad Nacional de Educación a Distancia. España. eduardogarcia1976@icloud.com

\section{Influenciar para construir las sombras de la realidad. Youtubers e Influencers en la Era Postdigital}

Autores: Javier Gil Quintana; Bárbara Castillo -Abdul,

Editorial Sindéresis, $1^{a}$ edición, 2020,

236 págs.

ISBN: 978-84-18206-43-6

\section{Resumen}

La obra reseñada ofrece una obra asociativa a través de nueve capítulos inéditos, en el que participaron veintidós docentes e investigadores norteamericanos. La publicación ofrece una visión panorámica e histórica del rol del influencer en la implementación de estrategias. Este libro muestra desde distintas vertientes de la comunicación corporativa, el Marketing, la publicidad y las relaciones públicas, como estos influenciadores asumen la responsabilidad de generar reputación, engagement, visibilidad y divulgación de contenidos de un modo más cercano con respecto a los stakeholders a través de diferentes redes sociales. Así mismo, aborda una serie de investigaciones que evidencian el comportamiento y la importancia de los canales disponibles en los entornos social media.

\section{Palabras clave}

Influenciadores; reputación; redes sociales;

\begin{abstract}
The reviewed book offers a collective work that presents nine unpublished chapters, in which twenty-two north American teachers and researchers participated. The publication offers a panoramic and historical vision of the role of the influencer in the implementation of strategies. This book shows, from different aspects such us corporate communication, marketing, advertising and public relations, how these influencers assume the responsibility of generating reputation, engagement, visibility and dissemination of content in a closer way to stakeholders through different social networks. It also has several researches that show the behavior and importance of the channels available in social media environments.
\end{abstract}

\section{Keywords}

$\begin{array}{lrr}\text { Influencer; } & \text { influencers; } & \text { reputation; } \\ \text { engagement; } & \text { social } & \text { network; } \\ \text { communication } & & \end{array}$


Javier Gil-Quintana es Doctor en Educación, cum laude y premio extraordinario por la Universidad Nacional de Educación a Distancia (UNED), ha trabajado como director y docente en centros públicos de Educación Infantil y Primaria, desarrollando proyectos de innovación educativa y recibiendo distintos reconocimientos al trabajo realizado. Ha ejercido como docente en la Universidad Católica de Ávila y, actualmente, es profesor de la Facultad de Educación de la UNED (Madrid). En el ámbito de investigación, participa en proyectos internacionales. Por su parte, Bárbara Castillo-Abdul es Doctoranda en el Programa Interuniversitario de Doctorado en Comunicación de las Universidades de Sevilla, Málaga, Huelva y Cádiz, bajo la línea de investigación "Educomunicación y Media Literacy".

El punto de partida esta obra es el prólogo de Carmen Marta-Lazo, introduciéndonos en las tecnologías de la relación, la información y la comunicación desde el factor relacional, situando la tecnología como esencia del humanismo, e introduciendo el concepto de la responsabilidad del líder en cada entorno sistémico para el equilibrio, y la transformación social, instándonos al pensamiento crítico mediante la adopción de la alfabetización mediática como defensa ante la pandemia informativa.

A partir de aquí el Dr. Javier Gil-Quintana en el primer capítulo, desglosa el papel de los influencers como reto social en la Era Postdigital, y el empoderamiento ciudadano a modo de nodo focal de la comunicación y los líderes de opinión, con la capacidad de influir en la toma de decisiones. Instándonos a proyectar una nueva sociedad mediante nuevos canales horizontales y bidireccionales alternativos a los impuestos, definiendo 10 elementos de identidad que debería tener un "ROL-influencer" para construir la nueva civilización basada en el humanismo y la solidaridad como son: propósito, singularidad, curiosidad, estrategia, pasión, amar lo que haces, servicio, colaboración del equipo, sencillez humildad y sentido del humor.

En el segundo capítulo del libro la Dra. Victoria Tur-Viñes y la Dra. María-José González-Río de la Universidad de Alicante, analizan YT como red social mediante un estudio cuali-cuantitativo proponiendo un nuevo indicador de interactividad del vídeo del canal de YT y concluyendo que YT no es una red social auténtica y qué interactuar en espacios con audiencias millonarias supone un difícil reto para los youtubers.

En el tercer capítulo Ana-María Beltrán-Flandoli de la Universidad Técnica Particular de Loja y Universidad de Huelva, Ana Larrea-Ayala de la Universidad de Cádiz; Vivían Ojeda-Serna, de Universidad de Huelva y Janina Ochoa-Mejía de la Universidad Técnica Particular de Loja, analizan IG mediante un estudio de las estrategias de posicionamiento de discurso, a través del análisis de los perfiles de dos profesoras, sus seguidores y el contenido publicado. Concluyendo que IG con fines educativos es una oportunidad para el discurso académico y un espacio propicio para el storytelling educativo.

En el capítulo cuarto la Dra. Carmen Cantillo-Valero de la UNED, la Dra. Margarita Roura-Redondo de la Universidad de Alcalá, y la Dra. Emelina Galarza-Fernández de la Universidad de Málaga, analizan el origen del feminismo, el personal branding y el empoderamiento y establecen el concepto de Fermvertising (feminismo + anunció) como pautas para eliminar el discurso patriarcal de la publicidad. Entienden, desde el Marketing del personal branding, una herramienta para empoderamiento femenino, y empoderamiento digital del mundo rural.

En el quinto capítulo Itziar Pedroche periodista de la Universidad Complutense Madrid, presenta los resultados de un estudio basado en análisis de los medios sociales en Emily Weiss, Into the Gloss y Gloisser, cuyo objetivo es comprender cómo la marca corporativa puede influir en la lealtad del cliente a través de un proceso de comunicación social; concluyendo que la clave es una estrategia de comunicación social en la que el público es el protagonista de la narración.

En el sexto capítulo Erika-Lucia González-Carrión de la Universidad Nacional de Loja, Ecuador y Andrea De-Santis-Piras de la Universidad Politécnica Salesiana, Cuenca, Ecuador, analizan IG como un recurso de comunicación corporativa, analizando el fenómeno influencer, desde las marcas cómo mecanismo de publicidad y empatizar con los clientes.

En el séptimo capítulo la Dra. Isabel Iniesta-Alemán de la Universidad de Zaragoza, aborda las estrategias de engagement, en la construcción de conexiones de calidad para un determinado público objetivo cuando sea relevante para el mismo. Concluyen, que ningún personaje o persona había alcanzado nunca la potencia de persuasión que la tecnología consigue para los actuales influencers.

En el octavo capítulo la Dra. Victoria Toribio-Lagar, el Dr. Rafael Marfil-Carmona y la Dra. Dolores ÁlvarezRodríguez del Depto. Didáctica Expresión Musical, Plástica y Corporal, Universidad Granada, evalúan los referentes de la moda en la adolescencia, mediante un análisis comparativo de los ídolos juveniles en España y la República Checa, constatando que los ídolos siguen siendo globales, y evidenciando la interiorización de la cultura digital y de las imágenes. 
Cierra esta obra, el capítulo noveno, de la Dra. Patricia de-Casas-Moreno de la Universidad Nebrija Daniela Jaramillo-Dent doctoranda de la Universidad de Huelva y Arantxa Vizcaíno-Verdú de la Universidad de Huelva. con un análisis de TIKTOK, mediante tres casos: Fortnite \#EmoteRoyale, Contest \#HariboChallenge y MAC \#YouOwnlt mediante \#Tiktokchallenges concluyendo que las organizaciones generan engagement en redes sociales como el compromiso cognitivo y afectivo del consumidor frente a la marca. Consiguiendo que las compañías creen estrategias de Marketing innovador.

Por último, en mi valoración, estamos ante un libro de referencia, que nos engancha desde el principio, con los cimientos del mito de la caverna de Platón, abriéndonos la mente al pensamiento crítico. Libro de lectura obligada para entender la figura del influencer asumiendo la responsabilidad de generar reputación, engagement, visibilidad y divulgación de contenidos de un modo más cercano, siendo este facilitador del cambio hacia una sociedad de comunicación horizontal, bidireccional que contribuya con ello a la democratización de la comunicación. Y abordando una serie de investigaciones que evidencian el comportamiento y la importancia de los canales disponibles en los entornos social media.

A mi juicio el libro deja abierto al lector la posibilidad de realizar nuevas investigaciones que lleven a la controversia de planteamientos como la necesidad de evaluar nuevos indicadores de medición de los impactos de los diferentes escenarios y redes en cuanto a contenidos y engagement.

Un libro, en definitiva, didáctico y que no defraudará a su lector y del que aconsejo su lectura, y porque no, su estudio. 